\title{
Staphylococcus aureus ST228 and ST239 as models for expression studies of diverse markers during osteoblast infection and persistence
}

\author{
Dafne Bongiorno ${ }^{1}$, Nicolò Musso ${ }^{1}$, Giuseppe Caruso $^{1}$, Lorenzo Lazzaro ${ }^{1}$, Filippo Caraci ${ }^{1}$, \\ Stefania Stefani ${ }^{1}$, and Floriana Campanile ${ }^{1}$ \\ ${ }^{1}$ University of Catania
}

October 2, 2020

\begin{abstract}
The ability of S. aureus to infect bone and osteoblasts is correlated to its incredible virulence armamentarium that can mediate the invasion/internalization process, cytotoxicity, membrane damage and intracellular persistence. We comparatively analyzed the interaction, persistence and modulation of expression of selected genes as well as cell viability in an ex-vivo model using human MG-63 osteoblasts of two previously studied and well-characterized S. aureus clinical strains belonging to ST239SCCmecIII-t037 and ST228-SCCmecI-t041 clones at $3 \mathrm{~h}$ and $24 \mathrm{~h}$ post-infection (p.i). ATCC12598 was used as a control strain. Using Imaging Flow Cytometry analysis, we found that strains differently invaded osteoblasts after 3h and 24h: ATCC12598 internalized in $70 \%$ and $50 \%$ of cells, ST239-SCCmecIII in $50 \%$ and $45 \%$ and ST228-SCCmecI in $30 \%$ and $20 \%$, respectively. ST239-III, during the infection period, exerted a significative cytotoxic activity due to the over-expression of hla and psmA and the increased expression of the genes involved in adhesion, probably due to the release and re-entry of bacteria inside MG-63 at $24 \mathrm{~h}$ p.i. The lower invasiveness of ST228-I was also correlated with the non-cytotoxic activity inside osteoblasts. This clone was not able to activate a sufficient cellular reaction and succumbed in-side the MG-63 cells.
\end{abstract}

Staphylococcus aureus ST228 and ST239 as models for expression studies of diverse markers during osteoblast infection and persistence

Dafne Bongiorno ${ }^{*}$, Nicolò Musso ${ }^{2 *}$, Giuseppe Caruso ${ }^{3 *}$, Lorenzo Mattia Lazzaro ${ }^{1}$, Filippo Caraci ${ }^{3,4}$, Stefania Stefani $^{1}$ and Floriana Campanile ${ }^{1}$.

${ }^{1}$ Department of Biomedical and Biotechnological Sciences (BIOMETEC) - Medical Molecular Microbiology and Antibiotic Resistance laboratory (MMARLab), University of Catania, 95125 Catania, Italy;

${ }^{2}$ Department of Biomedical and Biotechnological Sciences (BIOMETEC), University of Catania, 95125 Catania, Italy;

${ }^{3}$ Oasi Research Institute - IRCCS, 94018 Troina (EN), Italy;

${ }^{4}$ Department of Drug Sciences, University of Catania, 95125 Catania, Italy;

* These authors equally contributed to the paper.

Corresponding Author:

Dafne Bongiorno

Department of Biomedical and Biotechnological Sciences (MMARL)

University of Catania 
Via Santa Sofia, 97

95123 Catania, Italy

Tel: +390954781238

Email: d.bongiorno@unict.it

\begin{abstract}
The ability of $S$. aureus to infect bone and osteoblasts is correlated to its incredible virulence armamentarium that can mediate the invasion/internalization process, cytotoxicity, membrane damage and intracellular persistence. We comparatively analyzed the interaction, persistence and modulation of expression of selected genes as well as cell viability in an ex-vivo model using human MG-63 osteoblasts of two previously studied and well-characterized $S$. aureus clinical strains belonging to ST239-SCCmec III-t037 and ST228-SCCmec I-t041 clones at $3 \mathrm{~h}$ and $24 \mathrm{~h}$ post infection (p.i). ATCC12598 was used as control strain. Using Imaging Flow Cytometry analysis, we found that strains differently invaded osteoblasts after 3h and 24h: ATCC12598 internalized in $70 \%$ and $50 \%$ of cells, ST239-SCCmec III in 50\% and $45 \%$ and ST228-SCCmec I in $30 \%$ and $20 \%$, respectively. ST239-III, during the infection period, exerted a significative cytotoxic activity due to the over-expression of hla and psm A and the increased expression of the genes involved in adhesion, probably due to the release and re-entry of bacteria inside MG-63 at $24 \mathrm{~h}$ p.i. The lower invasiveness of ST228-I was also correlated with the non-cytotoxic activity inside osteoblasts. This clone was not able to activate a sufficient cellular reaction, and succumbed inside the MG-63 cells.
\end{abstract}

Keywords : MRSA, ST228, ST239, osteoblast, cross-talk mechanism, virulence toxin.

\title{
Introduction
}

Staphylococcus aureus is one of the main adaptable human pathogens, able to infect every organ and damage tissues, causing severe infections and able to resist antibiotics, in particular beta-lactams and methicillin. It is one of the main pathogens responsible for recurrent osteomyelitis (OM), accounting for more than $50 \%$, and prosthetic joint infections (PJIs) (Wu et al ., 2019; Tuchscherret al ., 2016). PJIs can have a dramatic impact on a patient's quality of life, often requiring surgical intervention and prosthesis removal, as well as prolonged antibiotics treatment (Stefani et al. , 2012; Purrello et al ., 2016; Moore et al ., 2017). These infections are often due to Healthcare-Associated Methicillin-Resistant S. aureus (HA-MRSA) belonging to Clonal Complex 5 (Peng et al., 2019; Muñoz-Gallego et al ., 2017; Perez-Montarelo et al. , 2018), and associated with Staphylococcal Chromosomal Cassette (SCCmec ) I and III (Hussain et al , 2009). Among them, ST239-III is probably the oldest pandemic MRSA clone, first discovered 1970, isolated in most countries all over the word and the most diffused in Europe and Italy (Moneke et al., 2018; Campanile et al. , 2015; Szymanek-Majchrzak et al ., 2018). The ST228-SCCmec I is one of the most diffused clones in Italy, associated with nosocomial infection (Campanile et al., 2012; Bongiorno et al., 2018).

The assessment of the interaction between $S$. aureus isolates and osteoblasts during PJIs and OM foresees three crucial events: adhesion, invasion and post-invasion, during which $S$. aureus controls the expression of adhesion and virulence determinants, with its large armamentarium of regulatory genes.

Many studies have been carried out in this field. Different authors have shown the role of many regulators involved in the invasion and adaptation to host tissue. The role of sig B in persistence and stress response, together with its link to sar A and consequently to its action on the agr locus was studied in osteoblasts, in anin-vivo model, using two different strains of $S$. aureus, in particular, the authors used the wild type and the defective strain for agr, sig B and sarA (Tuchscherr et al ., 2015). In fact, the global regulatory system agr locus - cell density-dependent controls virulence factor expression. Through its effector molecule RNAIII, the agr locus controls the post-transcriptional regulation of proteins involved in cell-surface interaction and virulence cytotoxic factors (Paiter et al ., 2014).

Two other genes belonging to the SARA protein family are involved in the regulation of virulence genes: $\operatorname{sarS}$ (SarH1), whose expression is repressed by sar A and $a g r$, is a repressor of hlaand etb and is a positive 
regulator of spa, androt, the "repressor of toxin", it is a repressor of enterotoxin B (seb) and alpha-toxin (hla ), and it is repressed by theagr effector RNAIII and SarA (Jenul and Horswill, 2018).

In the process of adhesion, cell surface proteins (adhesins) of the Microbial Surface Component Recognizing Adhesive Matrix Molecules (MSCRAMM), play an important role in the pathogenesis of osteoarticular (OM and PJ) infections. Among these, fibronectin binding proteins A and B (FnbA/B), fibrinogen-binding protein clumping factors $\mathrm{A}$ and $\mathrm{B}(\mathrm{ClfA} / \mathrm{B})$, the bone sialoprotein binding protein (Bbp), the collagen-adhesin (CNA) (Perez-Montarelo et al., 2018; Otsukaet al. , 2006) and SdrE, a serine-aspartate (SD) protein that anchors the cell-wall interacting with complement Factor $\mathrm{H}$ and facilitates colonization through adherence to the cell surface or extracellular matrix (ECM) components (Herr and Thorman, 2017).

$S$. aureus can invade endothelial cells and osteoblasts using cell surface integrin $\alpha 5 \beta 1$, binding Fn on the surface of human cells. In particular, as already demonstrated, FnBPA and FnBPB are involved not only in adhesion but also in internalization (Shnji et a l., 2011). Pore-forming proteins, such as Panton-Valentine leukocidine (PVL) and $\alpha$ - and $\delta$-hemolysin (Hla and Hld) together with phenol-soluble modulins (PSMs), were able to induce local complications such as bone deformation, systemic complications such as severe sepsis in rabbit osteomyelitis, or neutrophil and osteoblast cytotoxicity in an ex vivo model. The hla gene was frequently present in strains associated with osteoarticular bacteremia (Perez-Montarelo et al. , 2018). PSMs are small peptides with amphipathic properties that destabilize the lipid bilayer, this activity is related to receptor-independent cytotoxicity to osteoblasts and specialized cells such as neutrophils. PSMs are also implicated in biofilm formation, in bacterial interference and in cell-cycle disruptions (Davido et al. , 2016).

S. aureus, during the infection process, is able to use alternative carbon sources and, in particular, Glucose6-phosphate (G6P); the uptake of this alternative carbon source is possible using the hexose phosphate antiporter UhpT (Yang et al. , 2016).

After having observed that the interaction, internalization and persistence during an osteo-blast ex-vivo infection is a strain-dependent process, we selected two strains belonging to different genetic backgrounds showing a preliminary different ability to internalize as a model of infection in order to study how they differentially adapt strategies to react to changing environmental conditions and how they adjust their virulence factor expression at the different times of infection inside the MG-63 cell line.

\section{Materials and Methods}

\section{Strains included in the study}

The study sample consisted of 2 invasive MRSA isolates already molecularly characterized by standard genotyping methods internationally recognized to define MRSA clones. These strains were selected from a large collection of $15 \mathrm{MRSA}$ strains phenotypically and molecularly (SCCmec -Spa type) characterized as previously reported (Campanileet al ., 2015; Bongiorno et al ., 2018) and tested for their ability to internalize and persist in MG-63 human osteoblasts (Bongiorno, Musso et al ., 2020).

The invasive isolate ATCC12598 (Cowan ST30-t076) (ATCC@ Standards Development Organization, LGC Standards S.r.l., Sesto San Giovanni, MI, Italy) was used, as previously describe, as a control strain for invasion and persistence assays and for the statistical analysis of the results obtained with the Imaging Flow Cytometry (IFC) as previously reported (Bongiorno, Musso et al., 2020).

agr, toxin and MSCRAMM characterization

Genomic DNA, used as a template for PCR amplification, was extracted with QIAamp ${ }^{\circledR}$ DNA Mini Kit (Cat No. 51306, Qiagen) following the manufacturer's instructions, with some modifications. Briefly, a bacterial suspension was centrifuged and the pellet was resuspended in 200ul physiological saline solution $0.9 \%$ and subjected to freezing and thawing twice. After centrifugation the bacteria pellet was resuspended in $180 \mu \mathrm{l}$ of enzyme solution: $20 \mathrm{mg} / \mathrm{mL}$ lysozyme (cat No. 10837059001 Sigma-Aldrich-Merck KGaA, Darmstadt, Germany) and $100 \mu \mathrm{g} / \mathrm{ml}$ lysostaphin (cat. No. L7386-15MG, Sigma-Aldrich-Merck KGaA) in TE buffer pH 
8.0 (cat.No. AM9849 Ambion, Invitrogen). After these changes, the indications provided by the manufacturer were followed.

Toxin and MSCRAMM genes included in the study and listed in table S1 were tested as previously described (Stefani et al. , 2009). Theagr locus was typed using a multiplex PCR assay (Gilot et al. , 2002). PCR for the cna gene was performed used the following primers in 5'-3': F- GGAAAACGACCAACTGAAATCAAAG, R- TCTGGCGTATATTTATTCGTCACAATC. PCR was performed at $57^{\circ} \mathrm{C}$, the product size was $239 \mathrm{bp}$, strain MW2 was used as internal control.

PCR amplification was carried out in a Veriti Thermal Cycler (Applied Biosystems, ThermoFisher, Italy) in a total volume of $25 \mu$ l containing $2 \times$ Multiplex PCR Master Mix (cat. No. BR0200804, biotechrabbit GmbH, Hennigsdorf, Germany), and 10ng template DNA.

\section{$\delta-\eta \epsilon \mu о \lambda \psi \sigma \imath \nu \pi \rho o \delta u_{\varsigma} \tau \imath o \nu$}

The $\delta$-hemolysis production was evaluated by cross-streaking perpendicularly our sample to $S$. aureus RN4220, using 5\% sheep blood agar Columbia base with $6 \mathrm{mg} /$ liter vancomycin, as previously described. The $S$. aureus reference strains Mu3 (hVISA) and MU50 (VISA) were used as controls for strong hemolysis activity, NRS149 (VSSA) was used as control for absent hemolysis activity (Cafisoet al ., 2012).

Eukaryotic cell culture preparation

Infection experiments were performed on the human osteosarcoma cell line MG-63 (ATCC ${ }^{\circledR}$ CRL- 1427, Standards Development Organization, LGC Standards S.r.l.), as previously described (Bongiorno, Musso et al ., 2020).

A single 6-well plate was used for the Imaging Flow Cytometry (IFC), a single 6-well plate was used for RNA extraction and a 96-well plate was used for the evaluation of eukaryotic cellular metabolism. All experiments were performed twice in triplicate.

Evaluation of the frequency of internalization and intracellular persistence by IFC

The internalization frequency was evaluated in a cell culture model of infection in MG-63 osteoblasts at a multiplicity of infection (MOI) of 100:1, as previously reported (Bongiorno, Musso et al ., 2020). In this work we evaluated, with IFC, bacterial internalization after $3 \mathrm{~h}$ p.i., and persistence after $24 \mathrm{~h}$ p.i, as previously reported (Bongiorno, Musso et al ., 2020). We acquired 10,000 events for each sample and as quality control we used the stained and not stained bacterial suspension to exclude autofluorescence; a negative control of infected, but not permeabilized cells, was also acquired to guarantee the exclusively intracellular localization of green spots. Acquisition analysis was driven by the powerful INSPIRE(r) and IDEAS(r) packages (Amnis, EMD Millipore, Seattle, WA, USA).

\section{Eukaryotic cellular metabolic assay}

To evaluate the metabolic status of MG-63 cells following infection with $S$. aureus for $3 \mathrm{~h}$ and $24 \mathrm{~h}$, we used the MTT ([3-(4,5-dimethylthiazol-2-yl)-2,5-diphenyltetrazolium bromide]) assay (Pedotti et al ., 2017; Fresta et al ., 2018). The formazan crystals obtained at the end of the procedure were dissolved by dimethyl sulfoxide and the Multiplate reader Synergy H1 (BioTek) was used to determine the colorimetric differences, detected as absorbance at $569 \mathrm{~nm}$, between samples. The values obtained for infected cells were expressed as the percent variation with respect to the cellular metabolic status detected in the control, not infected, cells (which represents 100\%).

qRT-PCR expression study

The expression level of transcription of some selected genes involved in the bacteria/osteoblast interaction. The primers, reported in table 1, were designed by the Flexi ${ }^{(\mathrm{r})}$ Vector Primer Design Tool. Real Time PCR experiments on total RNA extracted from infected cell cultures, was carried out after $3 \mathrm{~h}$ and $24 \mathrm{~h}$ p.i. 
RNA extraction was performed using the RNeasy mini-kit (Cat No.74104, Qiagen, Milan, Italy) following the manufacturer's instructions, with some modifications. Briefly, bacteria internalized in MG-63 at 3h and 24h p.i. were collected in 500ul in RNAprotect Bacteria buffer (Cat No.76506, Qiagen) this first reaction series was carried out at a controlled temperature of about $4 \mathrm{degC}$, vortexed and incubated for $5 \mathrm{~min}$ at room temperature. After centrifugation the pellet was resuspended in $100 \mathrm{ul}$ of TE buffer containing: 20ul QIAGEN Proteinase K (Cat No.9131, Qiagen), lysozyme (cat No. 10837059001 Sigma-Aldrich-Merck KGaA, Darmstadt, Germany) $150 \mathrm{mg} / \mathrm{mL}$ and lysostaphin (cat. No. L7386-15MG, Sigma-Aldrich-Merck KGaA) 20 $\mathrm{mg} / \mathrm{mL}$. After these changes, the indications provided by the manufacturer were followed.

The RNA quality was tested by Qubit(r) 3.0 Fluorometer (Cat No. Q33216, life Technologies, Thermo Fisher Scientific Monza, Italy) using Qubit RNA HS Assay Kit $(250 \mathrm{pg} / \mu \mathrm{l}$ and $100 \mathrm{ng} / \mu \mathrm{l})$. The RNA was normalized at $100 \mathrm{ng}$, to obtain the cDNA, using the QuantiTect reverse transcription kit (Cat No. 205311, Qiagen) and the amplifications were performed using QuantiTect Syber Green PCR Kit (Cat. No.204145, Qiagen) using a cDNA final concentration of $25 \mathrm{ng} / \mathrm{ul}$ and $2 \mathrm{uM}$ primers per PCR reaction. Each sample amplification consisted of a total reaction volume of $10 \mu \mathrm{L}(5 \mu \mathrm{L}$ PCR Master Mix $+1 \mu \mathrm{L}$ specific primers $+4 \mu \mathrm{L}$ of cDNA $(25 \mathrm{ng} / \mathrm{ul})$. Reactions were run in triplicate using the following conditions: PCR initial activation step $15 \min 95^{\circ} \mathrm{C}$; denaturation $15 \mathrm{~s} 94^{\circ} \mathrm{C}$; annealing $30 \mathrm{~s} 60^{\circ} \mathrm{C}$; extension $30 \mathrm{~s} 72^{\circ} \mathrm{C}$, the acquisition of fluorescence was done for 50 Cycle. The negative control consisted of a reaction in the absence of cDNA $(5 \mu \mathrm{L}$ PCR Master Mix $+1 \mu \mathrm{L}$ specific primers $+4 \mu \mathrm{L}$ of Tris-EDTA buffer) indicated as NTC (no template control).

qPCRs were performed in a Light Cycler ${ }^{\circledR} 480$ Real Time PCR System (Roche, Monza, Italy). PCR efficiencies, melting curve analysis and expression rate were calculated using the Light Cycler ${ }^{\circledR} 480$ Software (Roche, Monza, Italy).gyr B primers were used as internal control.

The relative RNA expression level for each sample was calculated using the $2^{\text {-CT }}$ method (threshold cycle (CT) value of the gene of interest vs CT value of the housekeeping gene) (Fresta et al., 2020). For accurate gene expression measurements with qRT-PCR, the results were normalized to the gir B housekeeping gene.

Statistical model

Statistical analysis and the relative graphs were made using GraphPadPrism 6 (GraphPad Software Inc., La Jolla, CA, USA).

The statistical significance of the cytofluorimetric analyses were assessed used using Student's t-test, the number of single cell events analyzed was never less than 9,980 cells out of 10,000 events at the outset. The significance threshold was set $p$-value [?]0.05 (significant), $p$-value [?]0.01 (highly significant), and $p$ -value [?]0.001 (extremely significant) (Bongiorno, Musso et al., 2020). The evaluation of the MTT assay statistical significance was assessed using ANOVA and Sidak's multiple comparisons test (post hoc test). The expression analysis statistical significance was assessed using Ordinary one-way ANOVA and Bonferroni's Multiple Comparison Test.

\section{Results}

Genotypical characteristics, agr typing and toxin detection

The molecular features of the strains in study are reported in table 2.

S.aureus ATCC12598 was associated with agr type III, while ST239-III was associated with agr type I and ST228-I was associated with agr type I. $\delta$-hemolysis production was observed in all strains with the exception of ST228-I.

Genes responsible for adhesion, such as $f n b \mathrm{~A}$, ica A, clf A/B, cna and $s d r$ E (the lastbeing responsible for platelet aggregation), were present in all strains. Clone ST228-I showed a pattern of toxin genes similar to ATCC12598 (luk-PV, seg, sei, sem ), also carrying enterotoxin A and O genes. All strains showed the presence of $h l d$, and $h l g$, and ST239-III carried, in addition, the $h l \mathrm{~b}$ gene. 


\section{Evaluation of bacterial intracellular internalization and persistence}

We previously demonstrated the power of Imaging Flow Cytometry (IFC) to precisely estimate the percentage of osteoblasts infected with $S$. aureus strains in a sample of 10,000 MG-63 cells. Here we report the internalization rate, expressed as percentage of internalization after $3 \mathrm{~h}$ of infection and the persistence rate after $24 \mathrm{~h}$ of infection (figures 1 and 2).

At $3 \mathrm{~h}$ p.i., ATCC12598 internalized in $70 \pm 17.04 \%$ of MG- 63 cells, a slightly lower ability to internalize was found for clone ST239-III (50.24 $\pm 2.26 \%$ ), while ST228-I showed the lowest internalization rate, accounting for $29.8 \pm 2.31 \%(\mathrm{p}=0.015)$. The lower ability to internalize of the ST228 strain was also evident comparing it to ST239 ( $\mathrm{p}=0.0004)$ (Figure 1). Persistence inside cells was measured after $24 \mathrm{~h}$ of incubation: $49 \pm 1.96 \%$ of ATCC12598 bacterial cells persisted inside MG-63 cells; the same ability to persist was found in clone ST239-III (45.2 $\pm 6.2 \%)$, while ST228-I showed a decreased rate of persistence, $20.7 \pm 1.80 \%(\mathrm{p}<0.0001)$. The lower ability to persist of ST228 was also evident comparing it to ST239 ( $\mathrm{p}=0.0028)$ (Figure 2).

Analysis of MG-63 cellular metabolic status

Alterations in human osteoblast metabolic status, induced during internalization and persistence, were evaluated in the same experimental condition, by analysing the cell viability of MG-63 cells at $3 \mathrm{~h}$ and $24 \mathrm{~h}$ p.i. (Table 3).

At 3h p.i., MG-63 infected with ATCC12598 and ST228 strains showed a statistically significant increase in their metabolic activity compared to the control MG-63 uninfected cells, respectively, of $+12.27 \%(\mathrm{p}<0.001)$ and $+7.57 \%(\mathrm{p}<0.05)$, whereas the ST239 strain induced only a slight decrease in metabolic activity $(-2.47 \%)$.

Comparing the cellular metabolic status of MG-63 infected with ST239vs ATCC12598, we found a statistically significant decrease $(\mathrm{p}<0.001)$, while no statistical difference was found comparing the toxicity of MG-63 cells infected with ST228 vs ATCC12598. A statistical difference in human cellular metabolic status was found by comparing MG-63 infected with ST239 and ST228 to each other $(\mathrm{p}<0.001)$ (Table 3A).

At 24h p.i., ATCC12598 and ST239 intracellular persistence induced a statistically significant decrease in metabolic activity of MG-63 cells, compared to the uninfected control cells, respectively, of $-7.11 \%(\mathrm{p}<0.05)$ and $-18.32 \%(\mathrm{p}<0.001)$, while the ST228 strain showed only a slight increase in metabolic activity $(+3.79 \%)$.

Comparing the cellular metabolic status of MG-63 infected with ST239 and ST228 vs ATCC12598, we found a statistically significant decrease $(\mathrm{p}<0.001)$. Statistically significative differences in MG-63 metabolic status was found by comparing the results obtained from cells infected with ST239 and ST228 $(\mathrm{p}<0.001)$ (Table 3B).

\section{Expression studies}

During the experiments of MG-63 infection, RNA was extracted and the expression of some regulatory, adhesion and toxin genes was evaluated after $3 \mathrm{~h}$ and $24 \mathrm{~h}$ of intracellular persistence, in comparison with the non-internalized bacteria (basal condition). All experiments were the average of three biological experiments and are reported in Figure 3 and Table 4, subdivided with respect to their function.

In ATCC12598, sig B was significantly up-regulated after 24h p.i,sar A and sar S were up-regulated after $3 \mathrm{~h}$ p.i. In particular, sig B gene mRNA expression showed a strong statistically significant increase at $24 \mathrm{~h}$ p.i. (+2.92 \pm 0.27 -fold change (fd); p[?] 0.001) vs the basal condition, and comparing $24 \mathrm{~h} v s$ $3 \mathrm{~h}$ p.i. (p[?] 0.01). sar A gene mRNA expression showed an increase at $3 \mathrm{~h}$ vs basal condition $(+4.4+-0.98 \mathrm{fd}, \mathrm{p}[?] \mathrm{l}$ 0.05) and a statistically significant decrease at $24 \mathrm{~h}$ vs basal condition $(+0.79+-0.36 \mathrm{fd}, \mathrm{p}[?]$ 0.05). sar $\mathrm{S}$ gene mRNA expression showed an increase at $3 \mathrm{~h}$ vs basal condition $(+7.45+-0.65 \mathrm{fd}, \mathrm{p}[?] \mathrm{0} 01)$ and a statistically significant decrease at $24 \mathrm{~h} v s$ basal condition $(+1.83+-0.45 \mathrm{fd}, \mathrm{p}[?] 0.01)$.

The rot gene was significantly down-regulated after $24 \mathrm{~h}$ p.i. only in the ST228 strain. rot gene mRNA expression of the ST228 strain showed a statistically significant decrease at $24 \mathrm{~h} v s$ basal condition $(+0.23+-$ $0.016 \mathrm{fd}, \mathrm{p}[?]$ 0.05) and vs 3h (p[?] 0.05). 
For the other genes involved in regulation, no other statistical differences were observed in any condition tested. Expression of the MSCRAMM genes were reported in Figure 4 and Table 4. All the MSCRAMM genes were differentially modulated in our sample.

In the ATCC12598 strain, fnb A gene mRNA expression showed a statistically significant increase at $3 \mathrm{~h}$ vs basal condition $(+4255.6+-1052.8 \mathrm{fd}, \mathrm{p}[?] \quad 0.05)$ and a statistically significant decrease at $24 \mathrm{~h}$ p.i. vs $3 \mathrm{~h}$ $(+86.9+-28.03 \mathrm{fd}, \mathrm{p}[?] \quad 0.05)$. sdr E gene mRNA expression showed a statistically significant increase at $3 \mathrm{~h}$ vsbasal condition $(+10.63+-2.48 \mathrm{fd}, \mathrm{p}[?] \quad 0.05)$ and a statistically significant decrease at $24 \mathrm{~h}$ p.i. vs $3 \mathrm{~h}$ (+1.55+- $0.1 \mathrm{fd}, \mathrm{p}[?]$ 0.05).

$b b p$ gene mRNA expression showed a statistically significant increase $(+2318.32+-801.5 \mathrm{fd}, \mathrm{p}[?] 0.05)$ in the ST239 strain at 3h p.i.vs basal condition, and at $24 \mathrm{~h}$ vs basal condition $(+2897.22+-156.12 \mathrm{fd}$, p[?] 0.05). For the $f n b \mathrm{~B}$ gene and the other strains, no other statistical differences were observed in each condition considered. Expression of toxin genes and the sugar phosphate antiporter gene are reported in Figure 5 and Table 4 .

psm A gene mRNA expression of the ATCC12598 strain showed a statistically significant increase $(+6.75+-$ $3.75 \mathrm{fd}, \mathrm{p}[?] \quad 0.05)$ at $3 \mathrm{~h}$ p.i.vs $24 \mathrm{~h}$. In the ST228 strain, it was statistically significantly up-regulated $(+32.84+-11.5 \mathrm{fd}, \mathrm{p}[?] \mathrm{0}$ 0.05) at 3h p.i vs basal condition.

hla gene mRNA expression showed a significant increase in the ATCC12598 strain $(+1308.64+-323.75 \mathrm{fd}$, p[?] 0.05$)$ at $3 \mathrm{~h}$ p.i. vsbasal condition and a statistically significant decrease comparing $24 \mathrm{~h} v s$ h p.i. (17.58+-6.4 fd; p[?] 0.05). In the ST239 strain, it showed a statistically significant increase at $3 \mathrm{~h}$ and $24 \mathrm{~h}$ when comparing 3h vs basal condition (4922.01+-840.23 fd, p[?] 0.01 and 26698.18+-130.85 fd, p[?] 0.001), and also when comparing $3 \mathrm{~h}$ vs $24 \mathrm{~h}$ (p[?] 0.001). hld gene mRNA expression showed a significant decrease in ATCC12598 at 24h vs basal condition (0.04+-0.04 fd; p[?] 0.05). For the other strains, in each condition considered, no statistically significant differences were observed. The mRNA expression of the uhp T gene showed a statistically significative difference only in the ATCC12598 strain, in particular an up-regulation when comparing $3 \mathrm{~h}$ vs basal condition (16.85+-1.5 fd; p[?] 0.05) and a down-regulation when comparing $24 \mathrm{~h}$ vs $3 \mathrm{~h}$ (5.32+-2.27 fd; p[?] 0.05).

\section{Discussion}

Internalization of $S$. aureus in non-phagocytic cells is an attractive field of study relying on the particular ability of the microorganism to generate chronic diseases.

The process of internalization includes different phases: in the early phase, microbial surface proteins (MSCRAMMs) are implicated in host-cell adhesion and invasion, fighting against the immune system and entering the deep tissue structure (Painter et al., 2014); subsequently, the pathogenicity and virulence of $S$. aureus is entrusted to the capacity to produce several virulence factors including enterotoxins (SEs) and toxic shock syndrome toxin-1 (TSST), pore-forming toxins (hemolysins; Panton Valentine Leukocidin; phenol-soluble modulins), exfoliative toxins (ETs), protein A, and several enzymes able to damage host cells by virtue of their cytotoxic/cytolytic activity and by modulating immune responses.

In a previous study, we analysed, by a highly performing IFC assay, the differential proclivity of the main staphylococcal clones to invade, internalize, and persist within human cells. In particular, we demonstrated that ST5-II, ST8-IV, and ST228-I showed a statistically significant lower aptitude to intracellular subsistence, while ST239-III and ST22-IVh isolates had intracellular frequencies equal to, or greater than, those of the invasive ATCC12598 strain, suggesting their possible role as invasive and persistent clones responsible for chronic and recurrent infections (Bongiorno, Musso et al ., 2020).

Based on the above observations, by using the same model of infections, we examined the differential expression of a set of genes responsible for the adhesion, invasion and internalization of two $S$. aureusclones (ST228-I and ST239-III) compared with the control ATCC12598 invasive isolate.

The pathotype gene profile of the two strains included in the study showed only few differences. 
S. aureus ST228 is one of the most predominant clones associated with orthopedic infection (Jain et al ., 2019) showing a high rate of virulence, drug resistance and longer duration of hospital stay. It exhibited two more enterotoxins (SEA and SEO), suggesting a potential augmented role in eliciting and deregulating the immune system of the host (Hussain et al., 2009).

Conversely, ST239 was the only strain carrying the hlb gene coding for a pore-forming toxin involved in chronic skin infections and phagosomal escape (Katayama et al ., 2013), and producing $\delta$-hemolysis, demonstrating that the agr locus is not defective.

To further investigate these differences, we evaluated the expression of a selected set of genes grouped into three different general categories, i.e. regulators, adhesion factors (the MSCRAMMs), and toxins (table 5). Moreover, to evaluate the metabolic activity of internalized bacteria, we evaluated a hexose phosphate antiporter for G6P. The expression of the regulator global network SigB, SarA, SarS, agr locus and Rot controls the expression of a set of virulence factors involved in adhesion and cytotoxic/cytolytic activities.

Genes responsible for invasiveness and persistence were analyzed comparing the ability to infect and internalize into MG-63 osteoblasts, according to their cytotoxic potential (by means of cellular metabolic status of infected MG-63 osteoblasts) and the expression levels of surface and secreted toxins, at 3h and 24h p.i.

As was preliminary observed and now confirmed (Bongiorno, Musso et al ., 2020), the ability of MSSA ATCC12598-ST30 and MRSA ST239-III to internalized and persist in MG-63 is very similar, while MRSA ST228-I behaves differently $(20.7 \pm 1.80 \%)$. These differences among clones were evaluated also by measuring the MG-63 metabolic status in terms of cytotoxicity, demonstrating that ST239 was immediately able to decrease the cell metabolic activity at $3 \mathrm{~h}$ p.i. maintaining it at $24 \mathrm{~h}$ p.i. The ATCC12598 clone was able to interfere with the cells at $24 \mathrm{~h}$ p.i., while ST228 only slightly affected the metabolic status of the cells.

These results are in agreement with other studies (Botelho et al ., 2019), demonstrating that the ST239 clone is able to adapt to diverse pathological conditions (diverse syndromes), undergoes genomic adaptations, developing a distinct pattern of virulence-associated genes.

Strain ATCC12598 was included as an invasive model. It displayed, at 3h p.i., a higher ability to infect and internalize into MG-63 human osteoblasts (70\%), associated with a significative increment of the cellular metabolic status compared to the uninfected cell-line. At $24 \mathrm{~h}$ p.i., despite the fact that intracellular persistence decreased to 50\%, ATCC12598 bacteria exerted a high intracellular cytotoxic activity against osteoblasts, as demonstrated by a decrease in the cellular metabolic status. The regulation of gene expression in ATCC12598, during internalization and, especially, during persistence steps, followed an expected scheme: a significant increase of the expression of the genes involved in the regulation to environmental stress (in particularsar A, sig B), resulting in the up-regulation of the expression of the genes involved both in adherence (in particular tofnb A and $s d r \mathrm{E}$ ) and virulence ( $p s m \mathrm{~A}$ and hla) at $3 \mathrm{~h}$ p.i, although rot, the toxin repressor gene, did not undergo statistically significant changes, this is still in line with the expression of toxins.

In particular, psm A and hla over-expression could be related to the $20 \%$ decrease in persistence; moreover, the over-expression of $\alpha$-hemolysin could enhance internalization and survival by modulating osteoblast expression of $\beta 1$ integrin, as previously reported (Goldmann et al ., 2016), and also could be involved in pore formation and cellular lysis, which could explain the cellular metabolism decrease associated with enhanced cytotoxic activity. This is in line with previous studies in which Hla expression was required for the pathogenesis of invasive disease (Oliveira et al., 2018). At 24h p.i there was an over-decrease in the expression of regulatory genes, with the exception of sig B, probably due to cellular stimulation, which results in a decrease of the expression of genes involved in adhesion ( $f n b \mathrm{~A}$ and $s d r \mathrm{E}$ ) and virulence ( $p s m \mathrm{~A}$ and hla ). We can conclude that for the ATCC12598 strain, all the events involving both adhesion/invasion and damage of host cells, occurred within $3 \mathrm{~h}$ p.i. Furthermore, its metabolism, adapted to intracellular conditions, showed an up-regulation of the alternative antiporter of carbon source (UhpT) at $3 \mathrm{~h}$ p.i., confirmed by the $12 \%$ increase in the cellular metabolic status; while there was a significant decrease in metabolism at $24 \mathrm{~h}$ p.i. vs $3 \mathrm{~h}$, confirmed by the loss of $-7.11 \%$ of the cell metabolic status. The down-regulation of hld gene 
expression in ATCC12598 leads us to conclude that it was not involved in cellular adaptation or invasion.

The strain belonging to ST239-III, which did not show any toxin gene (Botelho et al ., 2019) except for sdr E presence, was able to infect (3h p.i.) $50 \%$ of MG-63 human osteoblasts, and induced a cellular metabolic slowdown activity, that could be due to the production of hemolysins Hlb, Hla, and PsmA. The ST239III strain displayed, at $3 \mathrm{~h}$ p.i., a significant increase of $b b p$ that is necessary for adhesion and invasion in MG-63 cells, and the increase of agr A expression, resulting in an up-regulation of hla and psm A, associated with a good ability to internalize and infect MG-63 cells. At 24h p.i., ST239-III bacteria stably persisted intracellularly (45\%) and exerted an extremely significative cytotoxic activity against osteoblasts, due to the over-expression of hla, as demonstrated by a remarkable decrease in the cellular metabolic status, also confirmed by the expression of the uhp $\mathrm{T}$ gene. Some studies have demonstrated the importance of this toxin for $S$. aureus pathogenicity, phagosomal escape and induction of biofilm formation (Katayama et al., 2013 ; Tajima et al., 2009). At 24h p.i there was an increased expression of the genes involved in adhesion. A possible explanation could be that the bacterial cells exit and enter MG-63 through the membrane, using the integrins located in the cell wall.

The significatively higher rates of intracellular invasion of ST239 bacteria could justify their cytotoxicity despite the loss of toxin production, and contribute to their survival in a higher number. These findings suggest that ST239 is associated with an intracellular adaptation that leads to decreased virulence and host immune escape, making this clone more prone to persistent infections.

During internalization and persistence, we did not find differences in the expression of the genes involved in the regulation to environmental stress ( $\operatorname{sar}$ A, sig B, sarS, agr ) and in those involved in adherence ( $f n b$ $\mathrm{A}$ and $f n b \mathrm{~B}$ ) with respect to the basal condition; this phenomenon could be probably due to the fact that these genes are normally over-expressed at the basal condition; while in the same condition, genes involved in toxicity and phagosomal escape (psm A and hla ) were down-regulated.

On the contrary, the strain belonging to ST228-I was found to be less able to internalize (30\%) after 3h p.i.; correlation analysis between regulatory genes and virulence factors showed that the ST228-I strain displayed at $3 \mathrm{~h}$ p.i. a basal level of agr A expression and an up-regulation of sig B and sar A, leading to an up-regulation of the surface-proteins and up-regulation of secreted toxins, such as PSM $\alpha$, Hla and Hld, associated with a significative non-cytotoxic activity inside osteoblasts, and a lower ability to internalize and infect MG-63 cells. Even if these variations were not statistically significant, their expression levels showed an expected scheme. This strain is also characterized by the presence of thepls gene, carried by SCCmec I, known to be involved in the failure to adhere to the cell surface (Hussain et al. , 2009).

After 24h of intracellular persistence, all the regulatory genes were down-expressed, in particular rot and consequently the genes involved in adhesion and virulence (except for an increased expression of $h l a$ at $3 \mathrm{~h}$ p.i.): $20 \%$ of MG-63 cells were infected and the cellular metabolic status did not show any variation with respect to the uninfected cell-line; the expression of $u h p \mathrm{~T}$ supported these results.

The impact of PSM $\alpha$ suggests that regardless of the lower invasiveness, ST228 bacteria exert their potential to damage osteoblasts by a cytotoxic effect. ST228 is not capable of activating a sufficient cellular reaction, rather it seemed to "succumb" inside the MG-63 cells. This variation in the expression of agr , sig B,hla and fnb A was previously associated with the passage from extracellular to intracellular behavior, due to changes in the expression of the fibronectin-binding protein and adhesion binding protein, important for host/cell invasion but difficult for intracellular persistence (Tuchscherr and Löffler, 2016).

Our results, arising from the qualitative and quantitative assays of virulence and toxin factors, are in line with recently published studies in which the genetic and phenotypic different characteristics of staphylococcal strains favor the infection process, invasiveness and persistence inside host cells (Davis and Isberg., 2018; Recker et al., 2017; Tuchscherr et al. , 2019). In our study, we analyzed two different genetic backgrounds to elucidate how bacteria can differentially adapt strategies with the interplay among regulatory and adhesion/toxin genes, and rapidly react to changing environmental conditions and dynamically adjust their virulence factor expression at different times of infection. Recent data from our group considering 
pro-inflammatory and pro-oxidant response in an ST239-III osteoblast infection, demonstrated a significant increase of gene expression of both interleukin- 6 and TNF- $\alpha$ (paper submitted). This ability was identified in this clone and not in others. The idea to consider new strategies, including the clonal approach, to treat $S$. aureusbone infection is being studied.

\section{Conclusion}

We found that the ST239-III clone was able to infect, at 3h p.i., 50\% of MG-63 human osteoblasts and these rates stably persisted at $24 \mathrm{~h}$ p.i.; during the infection peri-od it exerted an extremely significative cytotoxic activity against osteoblasts, due to the over- expression of hla and psm A, as demonstrated by a remarkable decrease in the cellular metabolic status. The increase of hla and psmA has as a consequence the increased of expression of the genes involved in adhesion ( $b b p)$, probably due to the release and re-entry of bacteria inside MG-63 at 24h p.i. Our results lead us to conclude that the ST239 clone is more prone to persistent infections.

On the contrary, ST228-I was found to be less able to internalize (30\%), with respect to the control strain and ST239-III, after $3 \mathrm{~h}$ p.i. and to persist (20\%) at $24 \mathrm{~h}$ p.i., and this lower in-vasiveness was also correlated with the non-cytotoxic activity inside osteoblasts. This is probably due to the presence of the pls gene into $\mathrm{SCC} m e c \mathrm{I}$, that is involved in the failure to adhere to the cell surface. This clone is not able to activate a sufficient cellular reaction, and succumbs inside the MG-63 cells.

Author contributions: Dafne Bongiorno : Conceptualization (equal); Investigation (equal); Methodology (equal); Project administration (lead); Validation (equal); Visualization (equal); Writing - original draft preparation (equal); Writing - review \& editing (equal). Nicolò Musso : Conceptualization (equal); Investigation (equal); Methodology (equal); Formal analysis (equal); Project administration (supporting); Validation (equal); Visualization (equal); Writing - original draft preparation (equal). Giuseppe Caruso: Investigation (equal); Methodology (equal); Formal analysis (equal); Validation (equal); Visualization (equal); Lorenzo Mattia Lazzaro : Investigation (supporting); Formal analysis (supporting); Filippo Caraci : Resources (equal);Stefania Stefani: Founding acquisition (equal);Resources (equal); Supervision (equal); Writing - review \& editing (equal). Floriana Campanile : Founding acquisition (equal); Conceptualization (equal); Resources (equal); Methodology (supporting); Supervision (equal); Writing - review \& editing (equal).

Acknowledgments: Some of the results of this study were presented at the 29th ECCMID (O0927) and at the 44th Italian Society of Microbiology (SIM) congress (P127). We would like to thank the BRIT laboratory at the University of Catania (Italy) for valuable technical assistance and use of their laboratories. We also wish to thank the Scientific Bureau of the University of Catania for language support. The manuscript was partially supported by: a research grant project number PRIN2017SFBFER from the Ministry of Research (MIUR) Italy; a research grant from a private company; a research grant entitled "Identification of cancer driver genes for novel diagnostics and therapeutic strategies - Piano per la ricerca 2016-2018 - Linea di intervento 2 - University of Catania, Dept. of Biomedical and Biotechnological Sciences".

Conflicts of Interest : The authors declare that the research was conducted in the absence of any commercial or financial relationships that could be construed as a potential conflict of interest.

Ethics statement : None required.

\section{References}

Bongiorno, D., Mongelli, G., Stefani, S., Campanile, F. (2018) Burden of Rifampicin- and MethicillinResistant Staphylococcus aureus in Italy. Microb Drug Resist : 24 : 732-738.

Bongiorno*, D., Musso*, N., Lazzaro, L.M., Mongelli, G., Stefani, S., Campanile, F. (2020) Detection of Methicillin-ResistantStaphylococcus aureus persistence in Osteoblasts using Imaging Flow Cytometry. Microbiologyopen . 2020 Apr 1: e1017. doi: 10.1002/mbo3.1017 
Botelho, A.M.N., Cerqueira, E., Costa, M.,O., Moustafa, A.,M., Beltrame, C.,O., Ferreira, F.,A., Côrtes, M.,F., Costa, B.,S.,S., Silva, D.,N.,S., Bandeira, P.,T., Lima, N.,C.,B., Souza, R.,C., de Almeida, L.,G.,P., Vasconcelos, A.,T.,R., Narechania, A., Ryan, C., O’Brien, K., Kolokotronis, S.,O., Planet, P.,J., Nicolás, M.,F., Figueiredo, A.,M.,S. (2019) Local Diversification of Methicillin- ResistantStaphylococcus aureus ST239 in South America After Its Rapid Worldwide Dissemination. Front Microbiol . 27 ; 10:82. doi: 10.3389/fmicb.2019.00082. eCollection 2019.

Cafiso, V., Bertuccio, T., Spina, D., Purrello, S., Blandino, G., Stefani, S. (2012) A Novel ס-Hemolysis Screening Method for Detecting Heteroresistant Vancomycin-Intermediate Staphylococcus aureus and VancomycinIntermediate S. aureus. J Clin Microbiol .50 (5): 1742-1744. doi: 10.1128/JCM.06307-11

Campanile, F., Bongiorno, D., Falcone, M., Vailati, F., Pasticci, M.B., Perez, M., Raglio, A., Rumpianesi, F., Scuderi, C., Suter, F., Venditti, M., Venturelli, C., Ravasio, V., Codeluppi, M., Stefani, S. (2012) Changing Italian nosocomial-community trends and heteroresistance inStaphylococcus aureus from bacteremia and endocarditis. Eur J Clin Microbiol Infect Dis . 31 (5):739-45. doi: 10.1007/s10096-011-1367-y. Epub 2011 Aug 7.

Campanile, F., Bongiorno, D., Perez, M., Mongelli, G., Sessa, L., Benvenuto, S., Gona, F.; AMCLI - S. aureus Survey Participants, Varaldo, P.E., Stefani, S. (2015) Epidemiology of Staphylococcus aureus in Italy: First nationwide survey, 2012. J Glob Antimicrob Resist . 3 (4):247-254. doi: 10.1016/j.jgar.2015.06.006. Epub 2015 Jul 29.

x, R., R. (2019) One for All, but Not All for One: Social Behavior during Bacterial Diseases. Trends Microbiol .27 (1):64-74. doi: 10.1016/j.tim.2018.09.001.

Fresta, C.G.; Chakraborty, A.; Wijesinghe, M.B.; Amorini, A.M.; Lazzarino, G.; Lazzarino, G.; Tavazzi, B.; Lunte, S.M.; Caraci, F.; Dhar, P.; Caruso, G. (2018) Non-toxic engineered carbon nanodiamond concentrations induce oxidative/nitrosative stress, imbalance of energy metabolism, and mitochondrial dysfunction in microglial and alveolar basal epithelial cells. Cell Death Dis 9: 245.

Fresta, C.G., Fidilio, A., Lazzarino, G., Musso, N., Grasso, M., Merlo, S., Amorini, A.M., Bucolo, C., Tavazzi, B., Lazzarino, G., Lunte, S.M., Caraci, F., Caruso, G. (2020) Modulation of Pro-Oxidant and ProInflammatory Activities of M1 Macrophages by the Natural Dipepti,de Carnosine. Int J Mol Sci. 21 (3). pii: E776. doi: 10.3390/ijms21030776.

Gilot, P., Lina, G., Cochard, T., Poutrel, B. (2002) Analysis of the genetic variability of genes encoding the RNA III-activating components Agr and TRAP in a population of Staphylococcus aureus strains isolated from cows with mastitis. J Clin Microbiol.40 (11):4060-7.

Herr, A.B., Thorman, A.W. (2017) Hiding in plain sight: immune evasion by the staphylococcal protein SdrE. Biochem J.474 (11):1803-1806.

Goldmann, O., Tuchscherr, L., Rohde, M., Medina, E. (2016) $\alpha$-Hemolysin enhances Staphylococcus aureus internalization and survival within mast cells by modulating the expression of $\beta 1$ integrin. Cell Microbiol . 18 (6):807-19.

Hussain, M., Schäfer, D., Juuti, K.M., Peters, G., Haslinger-Löffler, B., Kuusela, P.I., Sinha B. (2009) Expression of Pls (plasmin sensitive) in Staphylococcus aureus negative for pls reduces adherence and cellular invasion and acts by steric hindrance. J Infect Dis .200 (1):107-17. doi: 10.1086/599359.

Jain, S., Chowdhury, R., Datta, M., Chowdhury, G., Mukhopadhyay, A.K. (2019) Characterization of the clonal profile of methicillin resistantStaphylococcus aureus isolated from patients with early post-operative orthopedic implant-based infections. Ann Clin Microbiol Antimicrob : 18 (1):8. doi: 10.1186/s12941-0190307-z.

Jenul, C., Horswill, A.R. (2018) Regulation of Staphylococcus aureus Virulence. Microbiol Spectr . 6 (1): 10.1128/microbiolspec.GPP3-0031-2018. 
Katayama, Y., Baba, T., Sekine, M., Fukuda, M., Hiramatsu, K., J. (2013) Beta-hemolysin promotes skin colonization by Staphylococcus aureus. Bacteriol . 195 (6):1194-203. doi: 10.1128/JB.01786-12.

Monecke, S., Slickers, P., Gawlik, D., Müller, E., Reissig, A., Ruppelt-Lorz, A., Akpaka, P.E., Bandt, D., Bes, M., Boswihi, S.S., Coleman, D.C., Coombs, G.W., Dorneanu, O.S., Gostev, V.V., Ip, M., Jamil, B., Jatzwauk, L., Narvaez, M., Roberts, R., Senok, A., Shore, A.C., Sidorenko, S.V., Skakni, L., Somily, A.M., Syed, M.A., Thürmer, A., Udo, E.E., Vremeră, T., Zurita, J., Ehricht, R. (2018) Molecular Typing of ST239MRSA-III From Diverse Geographic Locations and the Evolution of the SCCmec III Element During Its Intercontinental Spread.

Front Microbiol . 6 ; 9:1436. doi: 10.3389/fmicb.2018.01436. eCollection 2018.

Moore, A.J., Whitehouse, M.R., Gooberman-Hill, R., Heddington, J., Beswick, A.D., Blom A.W., Peters, T.J. (2017) A UK national survey of care pathways and support offered to patients receiving revision surgery for prosthetic joint infection in the highest volume NHS orthopaedic centres. Musculoskeletal Care : 15 : 379-385. doi: $10.1002 / \mathrm{msc} .1186$.

Muñoz-Gallego, I., Lora-Tamayo, J., Pérez-Montarelo, D., Brañas, P., Viedma, E., Chaves, F. (2017) Influence of molecular characteristics in the prognosis of methicillin-resistant Staphylococcus aureusprosthetic joint infections: beyond the species and the antibiogram. Infection. 45 (4):533-537. doi: 10.1007/s15010-017-10116. Epub 2017 Apr 7.

Oliveira, D., Borges, A., Simões, M. (2018) Staphylococcus aureusToxins and Their Molecular Activity in Infectious Diseases. Toxins 10 (6). pii: E252. Review. doi: 10.3390/toxins10060252.

Otsuka, T., Saito, K., Dohmae, S., Takano, T., Higuchi, W., Takizawa, Y., Okubo, T., Iwakura, N., Yamamoto, T. (2006) Key adhesin gene in community-acquired methicillin-resistant Staphylococcus aureus .Biochem Biophys Res Commun . 346 (4):1234-44. Epub 2006 Jun 15. doi: 10.1016/j.bbrc.2006.06.038.

Painter, K.L., Krishna, A., Wigneshweraraj, S., Edwards, A.M. (2014) What role does the quorum-sensing accessory gene regulator system play during Staphylococcus aureus bacteremia? Trends Microbiol .22 (12):67685. doi: 10.1016/j.tim.2014.09.002. Epub 2014 Oct 6.

Pedotti, S., Ussia, M., Patti, A., Musso, N., Barresi, V., Condorelli, D. F. (2017) Synthesis of the ferrocenyl analogue of clotrimazole drug. Journal of Organometallic Chemistry, 830 : 56-61.

Peng, K.T., Huang, T.Y., Chiang, Y.C., Hsu, Y.Y., Chuang, F.Y., Lee, C.W., Chang, P.J. (2019) Comparison of Methicillin-ResistantStaphylococcus aureus Isolates from Cellulitis and from Osteomyelitis in a Taiwan Hospital, 2016-2018. J Clin Med . 7;8 (6). pii: E816. doi: 10.3390/jcm8060816.

Pérez-Montarelo, D., Viedma, E., Larrosa, N., Gómez-González, C., Ruiz de Gopegui, E., Muñoz-Gallego, I., San Juan, R., Fernández-Hidalgo, N., Almirante, B., Chaves, F. (2018)

Molecular Epidemiology of Staphylococcus aureus Bacteremia: Association of Molecular Factors with the Source of Infection.Front Microbiol . 9 :2210. doi: 10.3389/fmicb.2018.02210. eCollection 2018.

Purrello, S. M., Garau, J., Giamarellos, E., Mazzei, T., Pea, F., Soriano, A., Stefani, S. (2016) MethicillinresistantStaphylococcus aureus infections: a review of the currently available treatment options. $J$ Glob Antimicrob Resist .7 :178-86. doi: 10.1016/j.jgar.2016.07.010.

Recker, M., Laabei, M., Toleman, M., S., Reuter, S., Saunderson, R., B., Blane, B., Török, M.,E., Ouadi, K., Stevens, E., Yokoyama, M., Steventon, J., Thompson, L., Milne, G., Bayliss, S., Bacon, L., Peacock, S.,J., Massey, R.,C. (2017) Clonal differences in Staphylococcus aureus bacteremia-associated mortality. Nat Microbiol .2 (10):1381-1388. doi: 10.1038/s41564-017-0001-x. Epub 2017 Aug 7.

Shinji, H., Yosizawa, Y., Tajima, A., Iwase, T., Sugimoto, S., Seki, K., Mizunoe, Y. (2011) Role of fibronectinbinding proteins A and B inin vitro cellular infections and in vivo septic infections by Staphylococcus aureus . Infect Immun79 (6):2215-23. doi: 10.1128/IAI.00133-11. Epub 2011 Mar 21. 
Stefani, S., Chung, D.R., Lindsay, J.A., Friedrich, A.W., Kearns, A.M., Westh, H., Mackenzie, F.M. (2012) Methicillin-resistantStaphylococcus aureus (MRSA): global epidemiology and harmonization of typing methods. Int J Antimicrob Agents :39 :273-82. doi: 10.1016/j.ijantimicag.2011.09.030. Epub 2012 Jan 9.

Stefani, S., Bongiorno, D., Cafiso, V., Campanile, F., Crapis, M., Cristini, F., Sartor, A., Scarparo, C., Spina, D., Viale, P. (2009) Pathotype and susceptibility profile of a community-acquired methicillin-resistant Staphylococcus aureus strain responsible for a case of severe pneumonia. Diagn Microbiol Infect Dis . 63(1):100-4. doi: 10.1016/j.diagmicrobio.2008.09.012.

Szymanek-Majchrzak, K., Mlynarczyk, A., Mlynarczyk, G. (2018) Characteristics of glycopeptide-resistant Staphylococcus aureusstrains isolated from inpatients of three teaching hospitals in Warsaw, Poland. Antimicrob Resist Infect Control . 7 :105. doi: 10.1186/s13756-018-0397-y. eCollection 2018.

Tajima, A., Iwase, T., Shinji, H., Seki, K., Mizunoe, Y. (2009) Inhibition of endothelial interleukin-8 production and neutrophil transmigration by Staphylococcus aureus beta-hemolysin. Infect Immun . 77 (1):327-34. doi: 10.1128/IAI.00748-08. Epub 2008 Oct 20.

Tuchscherr, L., Pöllath, C., Siegmund, A., Deinhardt-Emmer, S., Hoerr, V., Svensson, C.M., Thilo Figge, M., Monecke, S., Löffler, B. (2019) Clinical S. aureus Isolates Vary in Their Virulence to Promote Adaptation to the Host. Toxins . 2019 Mar 1;11(3). pii: E135. doi: 10.3390/toxins11030135.

Tuchscherr, L., Löffler, B. (2016) Staphylococcus aureusdynamically adapts global regulators and virulence factor expression in the course from acute to chronic infection. Curr Genet. :62 : 15-17. doi: 10.1007/s00294015-0503-0. Epub 2015 Jun 30.

Tuchscherr, L., Bischoff, M., Lattar, S.M., Noto Llana, M., Pförtner, H., Niemann, S., Geraci, J., Van de Vyver, H., Fraunholz, M.J., Cheung, A.L., Herrmann, M., Völker, U., Sordelli, D.O., Peters, G., Löffler, B. (2015) Sigma Factor SigB Is Crucial to Mediate Staphylococcus aureus Adaptation during Chronic Infections. PLoS Pathog .11 (4): e1004870. doi: 10.1371/journal.ppat.1004870. eCollection 2015 Apr.

Wu, S., Huang, F., Zhang, H., Lei, L. (2019) Staphylococcus aureus biofilm organization modulated by YycFG two-component regulatory pathway. J Orthop Surg Res . 8;14 (1):10. doi: 10.1186/s13018-018-1055-z.

Yang, Y., Sun, H., Liu, X., Wang M., Xue, T., Sun, B. (2016). Regulatory mechanism of the three-component system HptRSA in glucose-6-phosphate uptake in Staphylococcus aureus . Med Microbiol Immunol .205 (3):241-53. doi: 10.1007/s00430-015-0446-6.

\section{Tables}

\section{Hosted file}

image1.emf available at https://authorea.com/users/363765/articles/484478-staphylococcusaureus-st228-and-st239-as-models-for-expression-studies-of-diverse-markers-duringosteoblast-infection-and-persistence

Table 1. Regulators, MSCRAMMs, toxins and other genes used to evaluate gene expression in Real Time PCR.

\section{Hosted file}

image2.emf available at https://authorea.com/users/363765/articles/484478-staphylococcusaureus-st228-and-st239-as-models-for-expression-studies-of-diverse-markers-duringosteoblast-infection-and-persistence

Table 2. Molecular characteristics of the samples included in the study. Clone characterization by means of: ST - Sequence Type; SCCmec - Staphylococcal Cassette Chromosome mec ;spa type - staphylococcal protein $\mathrm{A}$; agr type - locusagr ; delta-hemolysis production. fnb A-fibronectin binding protein $\mathrm{A}$; ica $\mathrm{A}$ Intracellular adhesion; sdr E- Platelet aggregation; clf A/B - clumping factor A/B; cna - Adesin binding to collagen; luk -PV - Panton-Valentine Leucocidin;eta / $b$ - Exfoliative toxin A/B; $h l b / d / g$-hemolysins 
Beta/Delta/Gamma; tst - Toxic shock syndrome toxin; se A-P - Staphylococcal enterotoxin from A to P; spa - protein A;agr - Accessory gene regulated.

\section{Hosted file}

image3.emf available at https://authorea.com/users/363765/articles/484478-staphylococcusaureus-st228-and-st239-as-models-for-expression-studies-of-diverse-markers-duringosteoblast-infection-and-persistence

Table 3 . Cellular metabolic status during infection and persistence. Cellular metabolic status was determined using the MTT assay. Data are the mean of at least 8 independent experiments and are expressed as the percent variation with respect to the cellular metabolic status detected in control, uninfected cells (100\%).A. Cellular metabolic status 3h p.i. B. cellular metabolic status at $24 \mathrm{~h}$ p.i. Statistical significance was assessed using ANOVA and Sidak's multiple comparisons test (post hoc test): significant (S) ${ }^{*} \mathrm{p}$ [?] 0.05 vs no bacteria; highly significant (HS) ${ }^{* *} \mathrm{p}<0.01$ vs no bacteria; extremely significant (ES) ${ }^{* * *} \mathrm{p}$ [?] 0.001

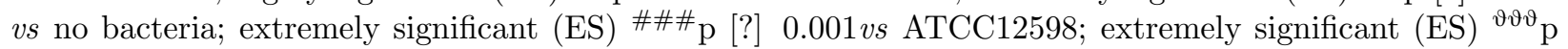
[?] 0.001 vs ST239-SCCmec III.

\section{Hosted file}

image4.emf available at https://authorea.com/users/363765/articles/484478-staphylococcusaureus-st228-and-st239-as-models-for-expression-studies-of-diverse-markers-duringosteoblast-infection-and-persistence

Table 4. The table reports the up/down regulations of the genes considered in the study, at $3 \mathrm{~h}$ and $24 \mathrm{~h}$ p.i. Statistically significant: $\mathrm{p}>0.05 \mathrm{~ns} ; p$-value [?]0.05*; highly significant [?]0.01**; extremely significant [?]0.001***.

\section{Hosted file}

image5.emf available at https://authorea.com/users/363765/articles/484478-staphylococcusaureus-st228-and-st239-as-models-for-expression-studies-of-diverse-markers-duringosteoblast-infection-and-persistence

Table 5. Comparison of $\%$ internalized MG-63, cellular metabolic status, adhesin and toxin gene regulation. Statistically significance: not significant (ns), p-value [?] $0.05 \mathrm{~ns}$; significant, p-value [?]0.05*; highly significant, p-value [?]0.01**; extremely significant, [?]0.001***

\section{Figure legend:}

Figure 1. Evaluation of the internalization frequency by IFC evaluation and cellular metabolism viability, after 3h p.i. at an MOI of 100:1. A. Percentage of spots per cell \pm SD for each strain for three different experiments. B . Detailed statistical data obtained using Student's t-test vs ATCC12598: p-value, 95\% confidence and R squared. Statistically significant p-value [?]0.05*; highly significant [?]0.01**; extremely significant [?]0.001***.

Figure 2 . Evaluation of the intracellular persistence by IFC evaluation and cellular metabolism viability, after 24h p.i. at an MOI of 100:1. A. Percentage of spots per cell +- SD for each strain for three different experiments. B. Detailed statistical data obtained using Student's t-test vs ATCC12598: $p$ - value, $95 \%$ confidence and $\mathrm{R}$ squared. Statistically significant $p$-value [?]0.05*; highly significant [?]0.01**; extremely significant [?]0.001***, more than extremely significant [?]0.0001****.

Figure 3. Evaluation of the relative mRNA expression of genes involved in regulation in ATCC12598, ST239 and ST228 strains after 3h and 24h p.i. vs basal condition. Horizontal bars report statistical analysis conducted vs ATCC12598 and between ST239 and ST228. Statistically significant $p$-value [?]0.05 *; highly significant [?]0.01**; extremely significant [?]0.001***. 
Figure 4 . Evaluation of the relative mRNA expression of the MSCRAMM genes in ATCC12598, ST239 and ST228 strains after $3 \mathrm{~h}$ and $24 \mathrm{~h}$ p.i. vs basal condition. Horizontal bars show statistical analysis conducted vs ATCC12598 and between ST239 and ST228. Statistically significant $p$-value [?]0.05*; highly significant [?]0.01**; extremely significant [?]0.001***.

Figure 5 . Evaluation of the relative mRNA expression of toxin genes in ATCC12598, ST239 and ST228 strains after $3 \mathrm{~h}$ and $24 \mathrm{~h}$ p.i.vs basal condition. Horizontal bars show statistical analysis conducted vs ATCC12598 and between ST239 and ST228. Statistically significant $p$-value [?]0.05*; highly significant [?]0.01**; extremely significant [?]0.001***.

\section{Appendices}

Table A1. MSCRAMMs, toxins and other genes used to evaluate the pathotype profile in qualitative PCR.

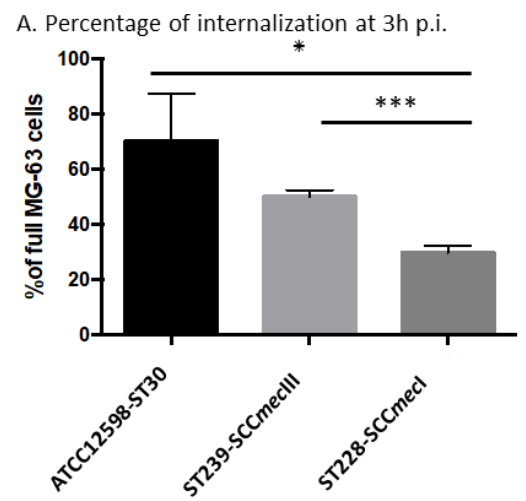

B. Statistical details of internalization at $3 \mathrm{~h}$ p.i.

\begin{tabular}{|c|c|c|c|}
\hline Student's t-test & $\begin{array}{c}\text { ST239-SCCmeclII } \\
\text { vs } \\
\text { ATCC12598-ST30 }\end{array}$ & $\begin{array}{c}\text { ST228-SCCmecl } \\
\text { vs } \\
\text { ATCC12598-ST30 }\end{array}$ & $\begin{array}{c}\text { ST228-SCCmecl } \\
\text { vs } \\
\text { ST239-SCCmecllII }\end{array}$ \\
\hline p-value & 0.1138 & $\underline{0.0152}$ & $\underline{0.0004}$ \\
\hline p value summary & ns & $*$ & $* * *$ \\
\hline Significantly different? ( $<<0.05)$ & No & Yes & Yes \\
\hline 95\% confidence interval & -47.57 to 7.527 & -68.02 to -12.90 & -25.62 to -15.26 \\
\hline R squared & 0.5044 & 0.8059 & 0.9677 \\
\hline
\end{tabular}

Figure 1. Evaluation of the internalization frequency by IFC evaluation and cellular metabolism viability, after $3 \mathrm{~h} \mathrm{p.i.} \mathrm{at} \mathrm{an} \mathrm{MOI} \mathrm{of} \mathrm{100:1.} \mathrm{A.} \mathrm{The}$ graph reports the percentage of spots for cell \pm SD for each strain for three different experiments. B. The table reports the detailed statistical data obtained using Student's t-test vs ATCC12598: $p$-value, 95\% confidence and R squared. Statistically significant $p$-value $\leq 0.05 *$; highly significant $\leq 0.01^{* *}$; extremely significant $\leq 0.001^{* * *}$. 
A. Percentage of intracellular persistance at $24 \mathrm{~h} p . i$.

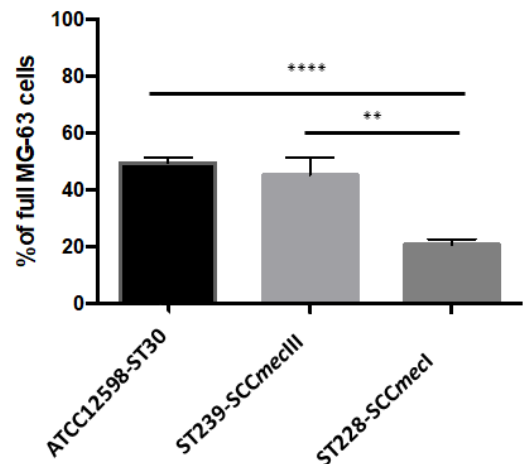

B. Statistical details of internalization at $24 \mathrm{~h}$ p.i.

\begin{tabular}{|c|c|c|c|}
\hline Student's t-test & $\begin{array}{c}\text { ST239-SCCmeclII } \\
\text { vs } \\
\text { ATCC12598-ST30 }\end{array}$ & $\begin{array}{c}\text { ST228-SCCmecl } \\
\text { vs } \\
\text { ATCC12598-ST30 }\end{array}$ & $\begin{array}{c}\text { ST228-SCCmecl } \\
\text { vs } \\
\text { ST239-SCCmecllII }\end{array}$ \\
\hline p-value & 0.3226 & $\leq 0.0001$ & $\underline{\mathbf{0 . 0 0 2 8}}$ \\
\hline p value summary & $\mathrm{ns}$ & $* * * *$ & $* *$ \\
\hline Significantly different? $(\mathbf{p}<\mathbf{0 . 0 5 )}$ & No & Yes & Yes \\
\hline 95\% confidence interval & -14.66 to 6.192 & -32.96 to -24.43 & -34.83 to -14.11 \\
\hline R squared & 0.2411 & 0.9887 & 0.915 \\
\hline
\end{tabular}

Figure 2. Evaluation of the intracellular persistence by IFC evaluation and cellular metabolism viability, after $24 \mathrm{~h}$ p.i. at an MOI of 100:1. A. The graph reports the percentage of spots for cell \pm SD for each strain for three different experiments. B. The table reports the detailed statistical data obtained using Student's t-test vs ATCC12598: $p$-value, 95\% confidence and R squared. Statistically significant $p$-value $\leq 0.05$

$*$; highly significant $\leq 0.01 * *$; extremely significant $\leq 0.001^{* * *}$, more than extremely significant $\leq 0.0001 * * * *$.
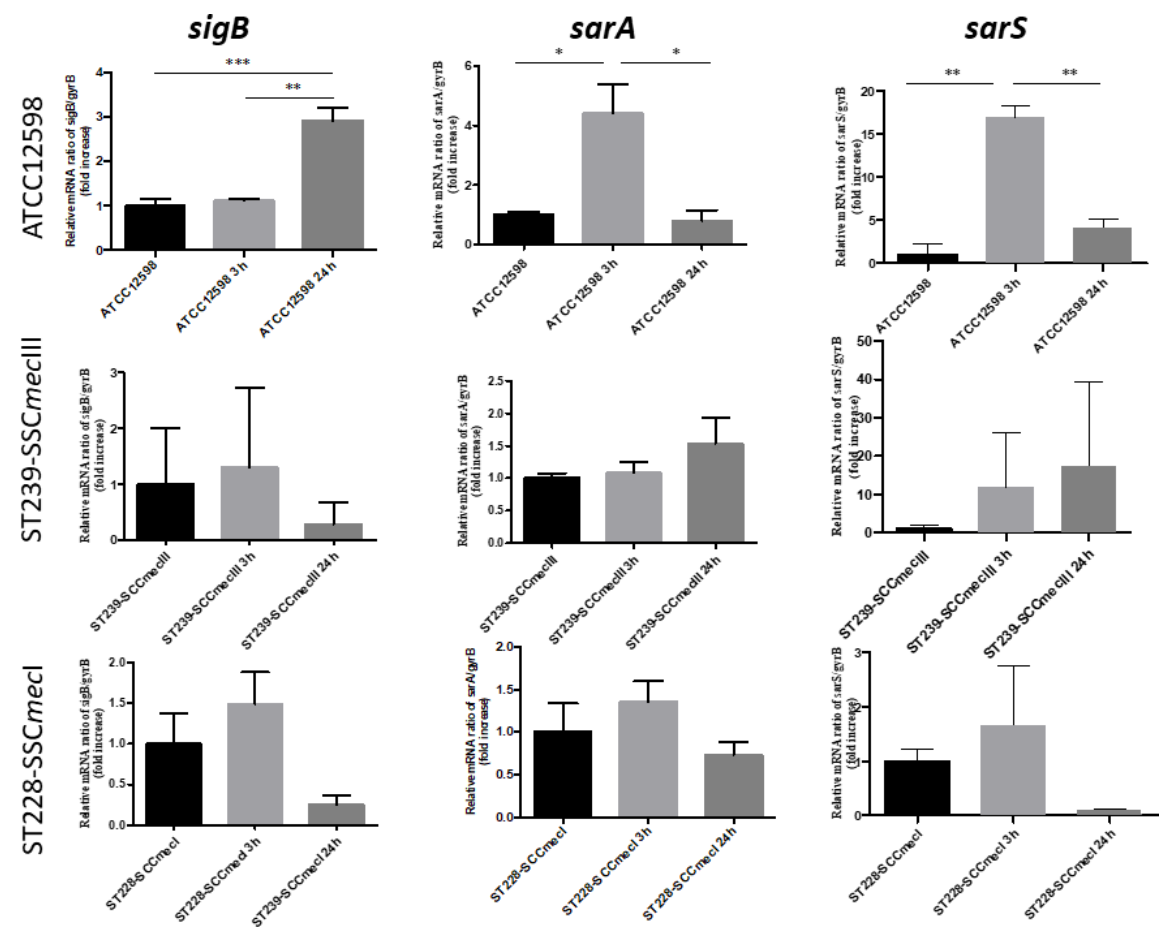

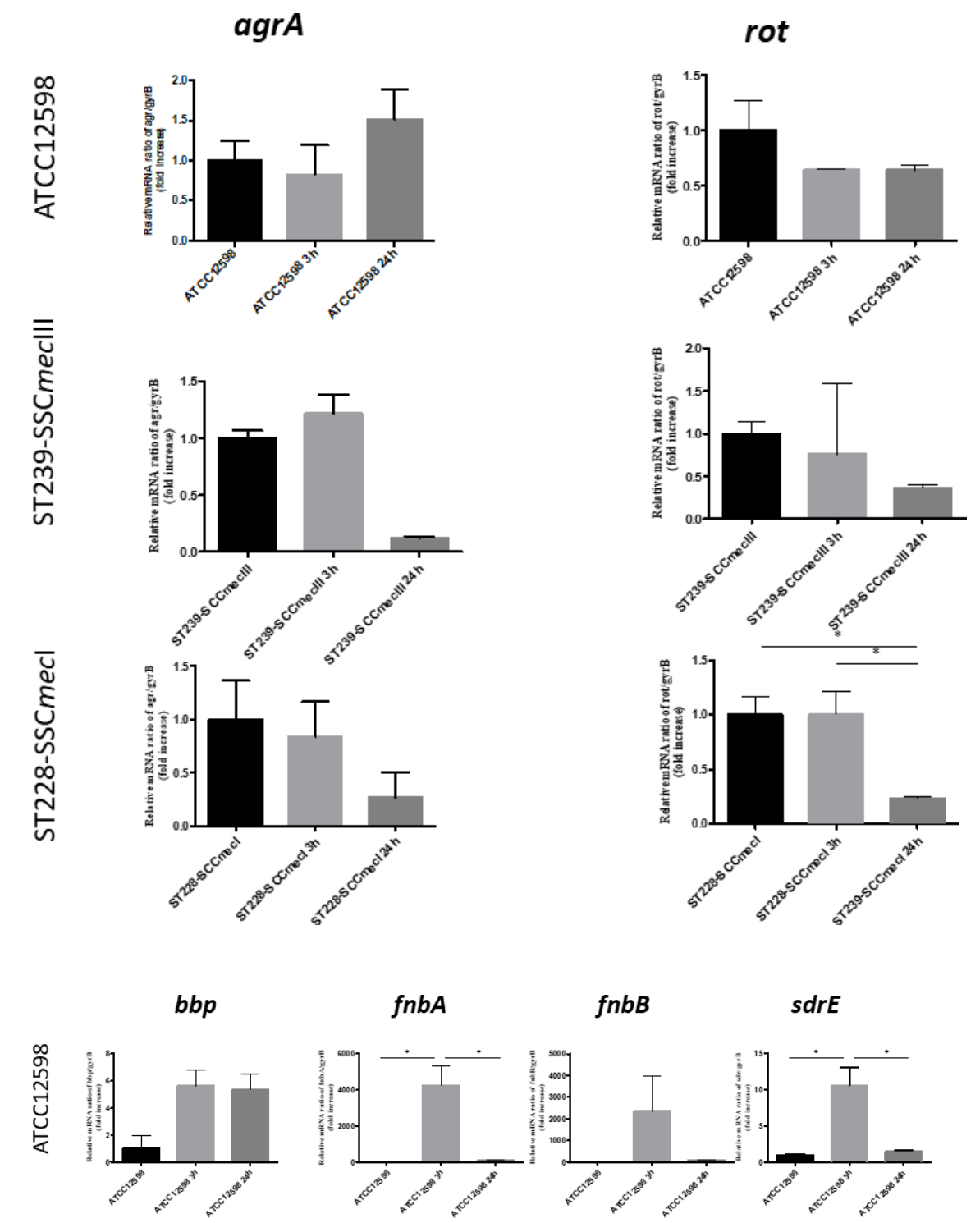

sdrE
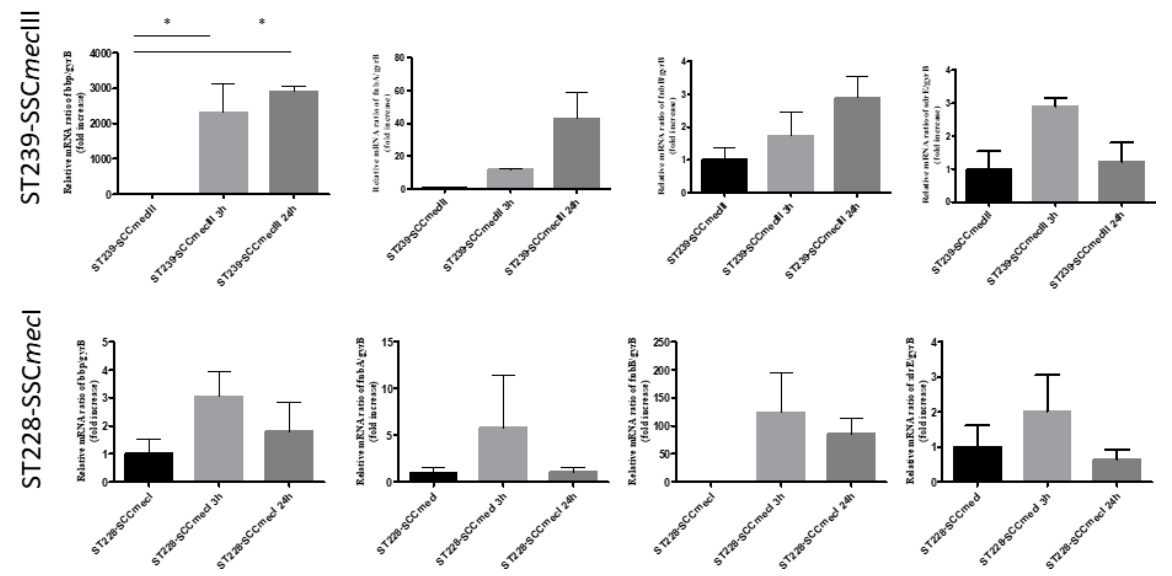


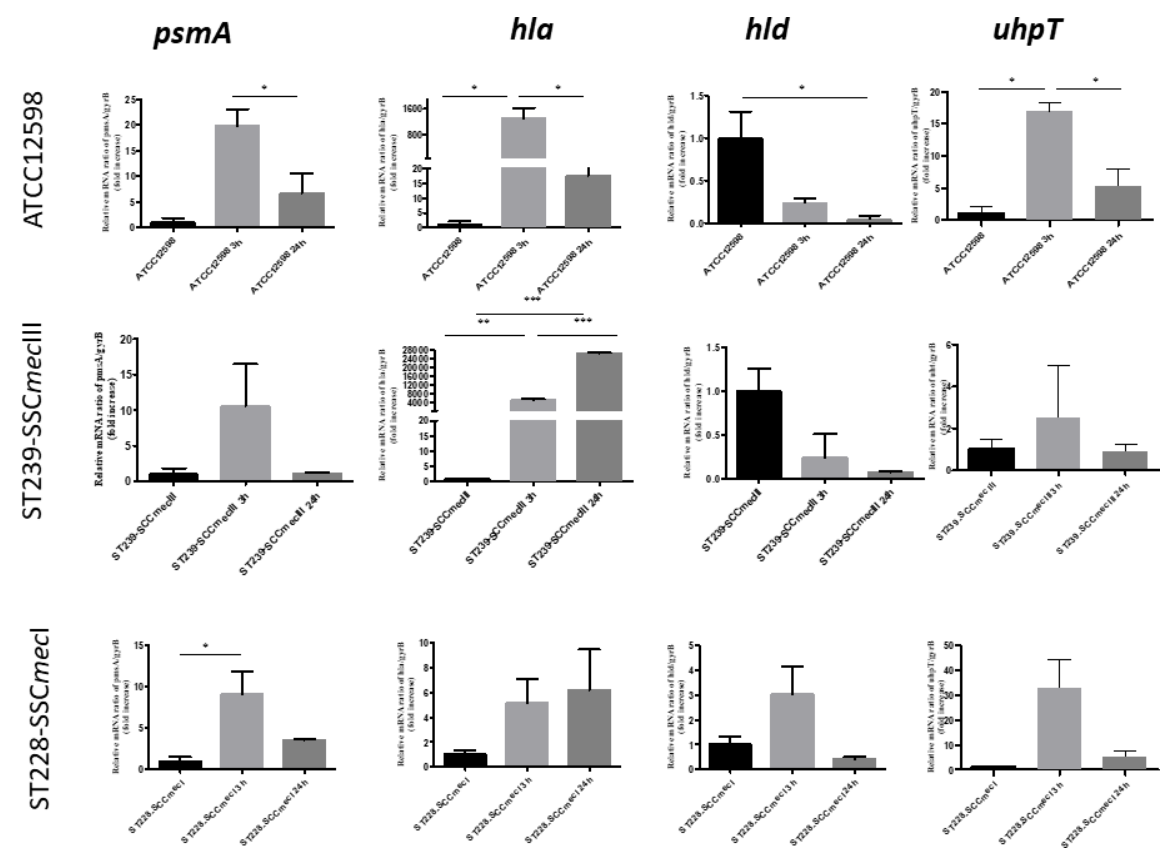

